\title{
A Case Study on Field Monitoring Analysis of Deep Foundation Pit in Soft Soils
}

\author{
Xiaoshuang Zhang $\mathbb{D}^{1}{ }^{1}$ Xiuchuan Zhang, ${ }^{2}$ and Yunshan Han ${ }^{1}$ \\ ${ }^{1}$ School of Science, North University of China, Taiyuan 030051, China \\ ${ }^{2}$ China Construction First Division Group Construction \& Development Co., Ltd., Beijing 100102, China \\ Correspondence should be addressed to Xiaoshuang Zhang; julie@nuc.edu.cn
}

Received 23 January 2019; Revised 4 April 2019; Accepted 14 April 2019; Published 2 May 2019

Academic Editor: Giovanni Biondi

Copyright ( 2019 Xiaoshuang Zhang et al. This is an open access article distributed under the Creative Commons Attribution License, which permits unrestricted use, distribution, and reproduction in any medium, provided the original work is properly cited.

\begin{abstract}
Field monitoring in the process of excavation of foundation pit is an important measure to reduce the risk. This paper describes a case study of the filed monitoring data during the process of deep foundation pit excavation in soft soil areas. The displacements of the diaphragm wall top were analysed and found that the horizontal displacement showed the convex shape, while the vertical displacement showed the concave shape. Based on the field monitoring data, the deformation mode of lateral displacement of the diaphragm wall belonged to the composite mode. The relationship between maximum lateral displacement and excavation depth showed a strong linear correlation. The horizontal displacements of bracing pillar decreased with the increasing of bracing stiffness, while the effect of bracing stiffness on vertical displacements of bracing pillar could be ignored. The settlement profile computed using the method of Hsieh and $\mathrm{Ou}$ was in good agreement with the field observations and better described the development trend of the ground surface settlement. The ratio of the maximum ground surface settlement $\left(\delta_{\mathrm{vm}}\right)$ to the maximum lateral displacement of the diaphragm wall $\left(\delta_{\mathrm{hm}}\right)$ was in the range of $0.74 \sim 0.88$, belonging to the range of $0.5 \sim 1.0$ proposed by $\mathrm{Hsieh}$ and $\mathrm{Ou}$. This paper provides a reference basis and related guidance for similar projects.
\end{abstract}

\section{Introduction}

As the development of urban construction and underground space exploitation scale, a large number of deep foundation pits appear in the construction of high-rise buildings and underground traffic engineering. Clearly, great attention needs to be paid to safety and serviceability. However, most deep foundation pits concentrate in urban areas with crowded structures, resulting in a complex construction environment. The need for construction of excavations in urban areas requires controlling of the surrounding ground movement since excessive ground movement may damage adjacent properties, even resulting in huge economic loss. The design concept of foundation pit in urban areas changes from strength control to deformation control. Field monitoring in the process of excavation of foundation pit is an important measure to reducing the risk, in addition to strengthening the bracing and retaining structure and improving the design level. At the same time, the field monitoring data provide an effective basis for dynamic adjustment of bracing parameters.

Generally, soil excavation causes the release of in situ stress and thus soil displacement [1-5], which inevitably exerts influence on existing structures. To better understand the influence of adjacent excavation on existing structures and deformation induced by the excavation of foundation pit, theoretical analysis, numerical analysis, and modelling tests have been conducted by many investigators [6-10]. For the prominent regional characteristics of foundation pit engineering, the general regularities of foundation pit deformation in different areas were proposed. Combining with field measuring data and numerical simulation method, the influence of a nearby large excavation on existing metro tunnels in Ningbo was investigated, and the measures, such as divided excavation, soil improvement, and cut-off wall, were also investigated to alleviate the influence of the 
adjacent excavation on the existing left tunnel [11]. In order to understand the deformation rule of the station and tunnel induced by the adjacent excavation in Shanghai, the close monitoring of the ground deformation and structure response was carried out [12]. The horizontal displacements of the retaining piles were monitored through the whole process of a deep excavation project in Tianjin, and the variation characteristics of deep soil displacement field induced by the four kinds of typical deformation model of retaining structure were also analysed [13].

Most research only provided a part of filed monitoring data, while the other data were obtained by using numerical simulation, in which exist certain deviations from the filed monitoring data. In this study, the variation regularities of the diaphragm wall deformation, horizontal and vertical displacement of bracing pillar, and ground surface settlement are analysed based on the filed monitoring data during the process of deep foundation pit project in soft soil areas. This paper provides a reference basis and related guidance for similar projects.

\section{Project Overview}

The foundation pit is located in Heping district, which is the city centre of Tianjin, China, and closely neighbouring Jiefang North Road, Xuzhou Road, Dagu North Road, and Kaifeng Road (Figure 1). The total building area of project is about $93556 \mathrm{~m}^{2}$, including a suite of commercial and official main tower, a two-floor modern shopping mall, and a fourfloor underground park.

The shape of foundation pit presents parallelogram roughly. The length and width of the foundation pit are both about $77 \mathrm{~m}$. The excavation depth in the podium region and main tower is $20.4 \mathrm{~m}$ and $21.7 \mathrm{~m}$, respectively, belonging to super and deep foundation pit. The excavation earthwork volume is approximately $142500 \mathrm{~m}^{3}$. The plan view illustrating the position and site photo of the foundation pit is shown in Figure 1. The roads around the foundation pit are important for the city traffic, and many buildings and underground pipelines are close to the foundation pit. To the north of the site, across Kaifeng Road, is Hisense Plaza, and the distance is $23 \mathrm{~m}$. To the west of the site, across Dagu North Road, is Binjiang Shopping Centre, and the distance is $36 \mathrm{~m}$. Other buildings lie to the south and east of the site. Hence, the construction environment is complex.

Field geomorphology belongs to the north China plain and eastern coastal plain landform. The subsurface conditions and soil properties at the site were obtained from the geotechnical investigation and laboratory tests, summarized in Table 1 . The site generally featured soft silty clays. The long-term phreatic water level was observed at depths of $2.2-2.5 \mathrm{~m}$.

\section{Construction Condition and Monitoring Scheme}

The retaining structure was a reinforced concrete diaphragm wall with the $0.8 \mathrm{~m}$ thick and $45 \mathrm{~m}$ deep. As shown in Figure 2, the strut used the circular reinforced concrete bracing system. The strut of the foundation pit is composed of four reinforced concrete bracing systems. The construction schedule of excavation and bracing is shown in Figure 3. The first bracing was installed on the capping beam at the top of the diaphragm wall, and three other bracings were installed on the waist beams in the specified position.

Earthwork followed the principle of excavation, which was bracing before excavation, layering, symmetry, balance, and time limit. Taking the excavation method in Tianjin as a reference, the centre island construction plan was adopted, i.e., excavation started from the peripheral soil outside the ring beam and ended at the central zone inside the ring beam for each excavation stage, which is opposite sequence of some centre island excavations reported by Tan $[14,15]$. Earthwork excavation was divided into five stages, and each bracing is divided into eight periods of construction. The excavation sequence was required to combine with the installation of local bracing system, in order to ensure that the time lag between excavation of part earthwork and corresponding construction of bracing structure was in the range of allowable design and to control the deformation of foundation pit and surrounding structures.

The monitoring was implemented in the whole construction process to effectively ensure the security of the foundation pit overall construction and timely understand of the influence of the foundation pit construction on the surroundings around foundation pit. Overall construction scheme can be dynamically adjusted according to the monitoring data and alarming value on monitoring.

Generally, the safety monitoring content of foundation pit includes the bracing system (diaphragm wall, internal bracing, etc.) and the surroundings around foundation pit (buildings, pipelines, etc.). Combining with the characteristics of engineering construction and deformation controlling requirements of security level, the construction and subsequent behaviour of the excavation were monitored by measuring displacement of the diaphragm wall top, deep horizontal displacement of the diaphragm wall, displacement of bracing pillar, and ground surface settlement, as shown in Figure 4.

The alarming value on monitoring of the bracing system is determined by engineering geological characteristics, designing scheme, and engineering experience, while the alarming value on monitoring of surroundings around the foundation pit is determined by the alarming value of surrounding buildings and pipelines, respectively. The alarming value on monitoring is controlled by the cumulative allowed variation and allowed variation in per unit time (variation rate). Considering the serious impact of bracing and retaining structure damage, soil mass failure, or excess deformation on surroundings around foundation pit, the security level of foundation pit should be classified as first order. According to the Technical Code for Monitoring of Building Foundation Pit Engineering (GB504972009), the alarming values on monitoring are the cumulative allowed variation of $30 \mathrm{~mm}$ or variation rate of $3 \mathrm{~mm} / \mathrm{d}$ for displacement of the diaphragm wall top, displacement of bracing pillar, and ground surface settlement, while the alarming value on monitoring is the cumulative allowed 


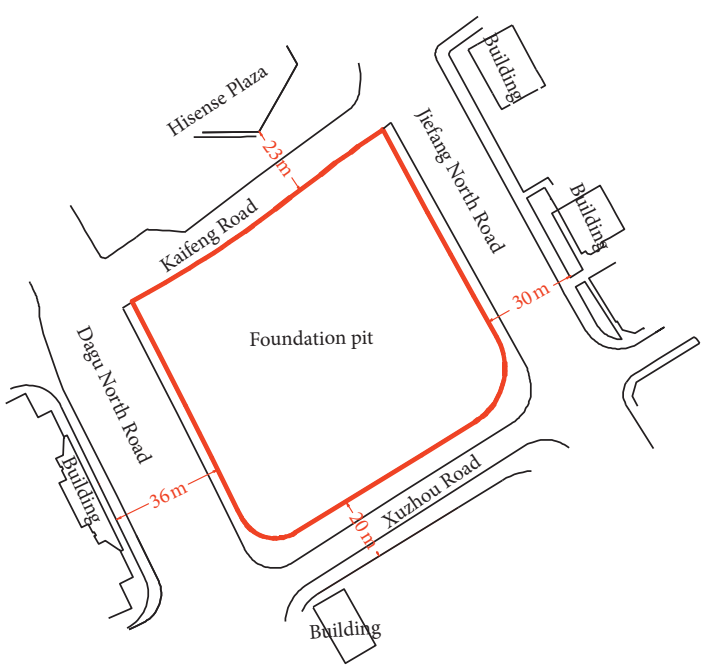

(a)

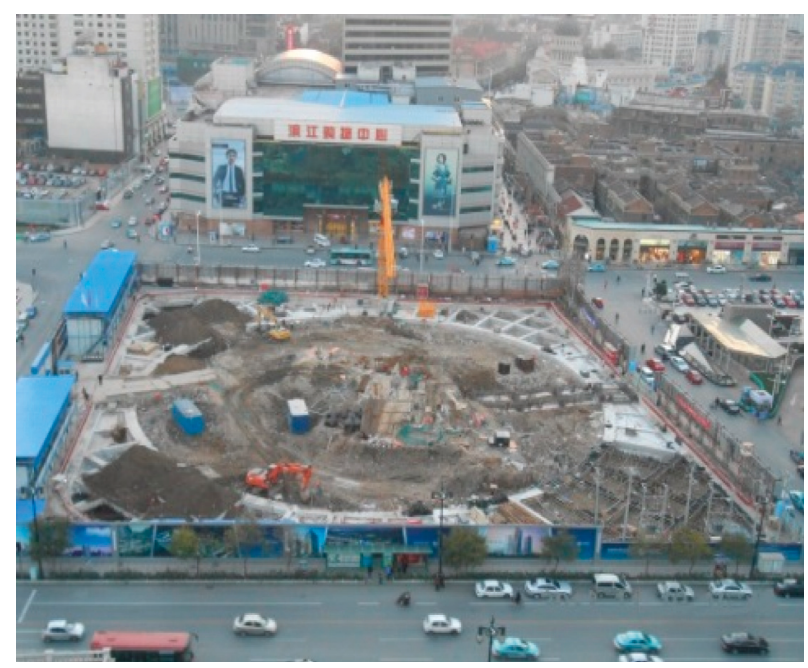

(b)

Figure 1: Plan view illustrating the position and site photo of the foundation pit. (a) Plan view. (b) Site photo.

Table 1: Physical and mechanical parameters.

\begin{tabular}{|c|c|c|c|c|c|c|c|c|}
\hline $\begin{array}{l}\text { Soil } \\
\text { classification }\end{array}$ & $\begin{array}{l}\text { Layer } \\
\text { thickness, } \\
(\mathrm{m})\end{array}$ & $\begin{array}{l}\text { Unit weight, } \\
\gamma\left(\mathrm{kN} / \mathrm{m}^{3}\right)\end{array}$ & $\begin{array}{c}\text { Cohesion, } \\
c(\mathrm{kPa})\end{array}$ & $\begin{array}{c}\text { Friction angle, } \\
\qquad \varphi\left({ }^{\circ}\right)\end{array}$ & $\begin{array}{c}\text { Characteristic value of } \\
\text { subsoil bearing capacity, } \\
f_{\mathrm{a}}(\mathrm{kPa})\end{array}$ & $\begin{array}{l}\text { Permeability } \\
\text { coefficients, } \\
k(\mathrm{~cm} / \mathrm{s})\end{array}$ & $\begin{array}{l}\text { Liquidity } \\
\text { index, } I_{\mathrm{L}}\end{array}$ & $\begin{array}{c}\text { Constrained } \\
\text { modulus, } E_{\mathrm{s}} \\
(\mathrm{MPa})\end{array}$ \\
\hline Backfill soils & 1.0 & 19.5 & 10.0 & 22.1 & 100 & $1.9 \times 10^{-7}$ & 0.75 & 4.49 \\
\hline Silty clays & 1.5 & 19.6 & 20.4 & 25.9 & 120 & $2.6 \times 10^{-7}$ & 0.71 & 5.87 \\
\hline Sandy silts & 2.1 & 19.4 & 22.2 & 40.6 & 135 & $7.1 \times 10^{-6}$ & 0.87 & 7.80 \\
\hline Sandy silts & 1.3 & 19.8 & 31.3 & 39.1 & 130 & $0.9 \times 10^{-5}$ & 0.82 & 13.69 \\
\hline Silty clays & 5.3 & 19.5 & 22.6 & 33.1 & 110 & $1.4 \times 10^{-6}$ & 0.95 & 6.72 \\
\hline Silty clays & 3.5 & 20.0 & 15.4 & 29.2 & 120 & $0.9 \times 10^{-6}$ & 0.67 & 4.84 \\
\hline Silty clays & 2.1 & 20.1 & 27.9 & 24.5 & 140 & $1.4 \times 10^{-7}$ & 0.58 & 5.35 \\
\hline Silty clays & 3.2 & 20.2 & 30.9 & 25.0 & 150 & $1.6 \times 10^{-7}$ & 0.57 & 5.60 \\
\hline Silty sands & 5.7 & 20.7 & 27.8 & 30.3 & 210 & $1.1 \times 10^{-5}$ & 0.53 & 14.34 \\
\hline Silty clays & 6.6 & 20.1 & 37.3 & 19.1 & 160 & $1.9 \times 10^{-7}$ & 0.44 & 5.82 \\
\hline Sandy silts & 7.1 & 20.5 & 28.5 & 40.7 & 220 & $1.1 \times 10^{-5}$ & 0.48 & 15.29 \\
\hline Silty clays & 2.7 & 20.3 & 32.3 & 25.9 & 200 & $0.5 \times 10^{-5}$ & 0.47 & 6.50 \\
\hline Sandy silts & 7.7 & 20.5 & 25.1 & 41.5 & 260 & $1.0 \times 10^{-5}$ & 0.60 & 13.07 \\
\hline
\end{tabular}

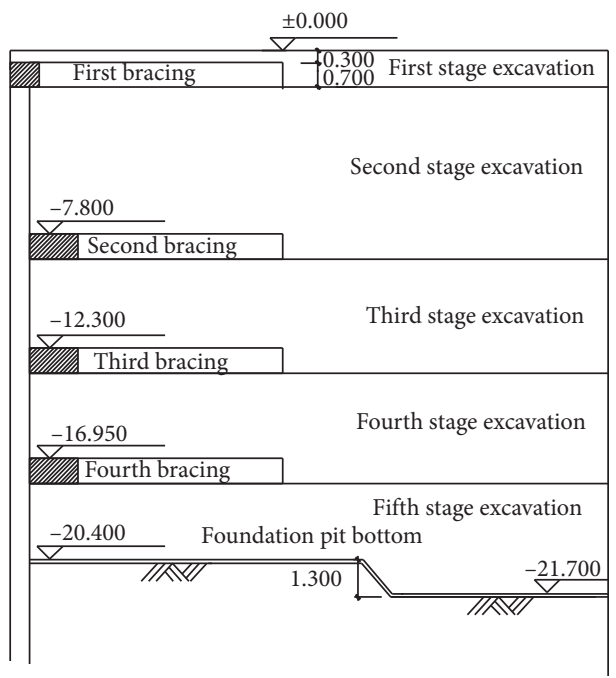

(a)

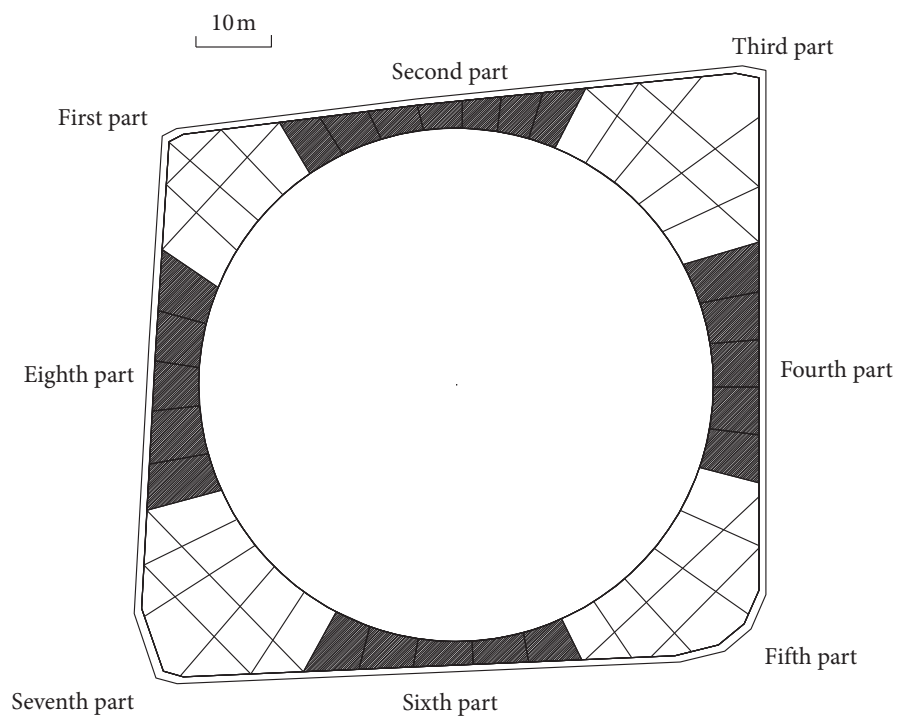

(b)

Figure 2: Sketch of the bracing and retaining structure (unit: m). (a) Profile view. (b) Plane view. 


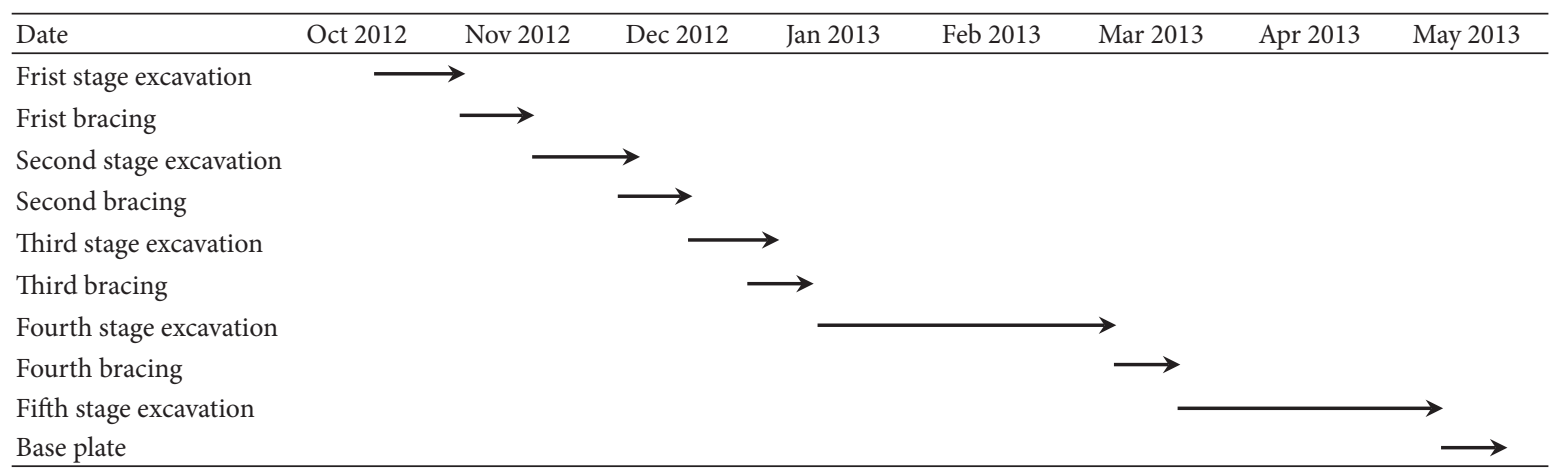

FIgURE 3: Construction schedule of excavation and bracing.

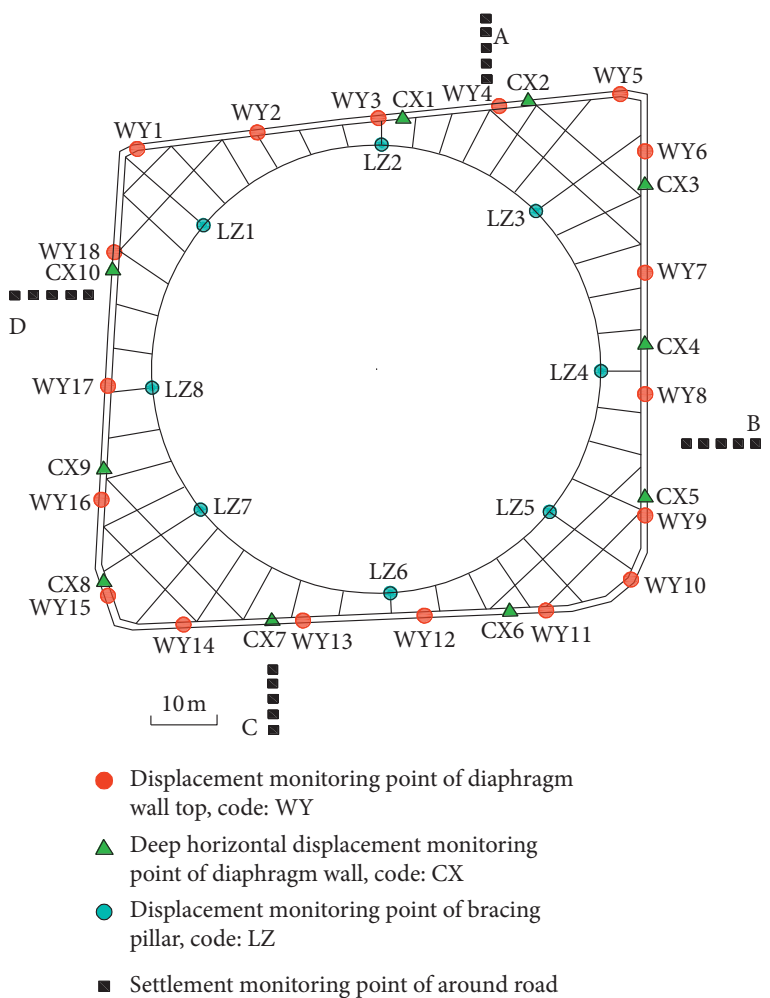

FIGURE 4: Instrumentation layout of the excavation in plane for field monitoring.

variation of $40 \mathrm{~mm}$ or variation rate of $3 \mathrm{~mm} / \mathrm{d}$ for deep horizontal displacement of the diaphragm wall.

\section{Analysis of Monitoring Results}

4.1. Diaphragm Wall Deformation. Figure 5 shows the various curves of the horizontal displacement of the diaphragm wall top at $B$ side during engineering construction. As shown in Figure 5(a), the horizontal displacement of the diaphragm wall top at B side increased slightly before finishing the third bracing with the increasing of excavation depth, and the maximum horizontal displacement of the diaphragm wall top at $B$ side varied in the range of $5 \sim 7 \mathrm{~mm}$. Then, the horizontal displacement of the diaphragm wall top at B side accumulated with an obviously increasing rate during the fourth and fifth stage excavations. When the fifth stage excavation was finished, the maximum horizontal displacement was $25 \mathrm{~mm}$ for monitoring point of WY8 and approximately $22 \mathrm{~mm}$ for other three monitoring points. The horizontal displacement of the diaphragm wall top at B side nearly remained the same during the construction of base plate.

As shown in Figure 5(b), the horizontal displacement of the diaphragm wall top at the same side rose before decreasing and showed convex shape. The monitoring point of the maximum horizontal displacement was located at the middle part of the diaphragm wall, which was mainly due to the space effect. The result is consistent with the trend reported by Tan $[16,17]$, i.e., the minimum $\delta_{\mathrm{hm}} / \mathrm{H}_{\mathrm{e}}$ occurred near the shaft corners and tended to increase with distance away from the corner. The inhibiting effect of foundation pit corner on horizontal displacement of the diaphragm wall top was more obvious when the monitoring point was close to the foundation pit corner. Comparing the horizontal displacement of the diaphragm wall top between the monitoring points WY5, WY14 and WY1, WY10, WY11 showed that the horizontal displacement of the diaphragm wall top near the foundation pit corner was smaller when the foundation pit corner was at a less angle, in other words, the space effect was more remarkable. The maximum horizontal displacement of the diaphragm wall top at different sides had slight difference ranging between 23 and $25 \mathrm{~mm}$, indicating that the deformation of diaphragm walls at different sides was almost symmetry. During construction, the horizontal displacement of the diaphragm wall top was less than the alarming value on monitoring and belonged to the safe range.

Figure 6 shows the various curves of vertical displacement of the diaphragm wall top at $B$ side during engineering construction. As shown in Figure 6(a), the vertical displacement of the diaphragm wall top was upheaval due to the stress release induced by excavation. The vertical displacement of the diaphragm wall top near foundation pit corner (WY6, WY9, and WY10) increased with the increasing of excavation depth, and the maximum value was in the range of $15.5 \sim 18.6 \mathrm{~mm}$. The vertical displacement of the diaphragm wall top increased slightly during base plate construction, which might be caused by soil creep. Ying and Yang [18] also presented the similar field monitoring phenomenon in soft soil area. Hence, the time for foundation pit without the base plate should be decreased as far as possible 


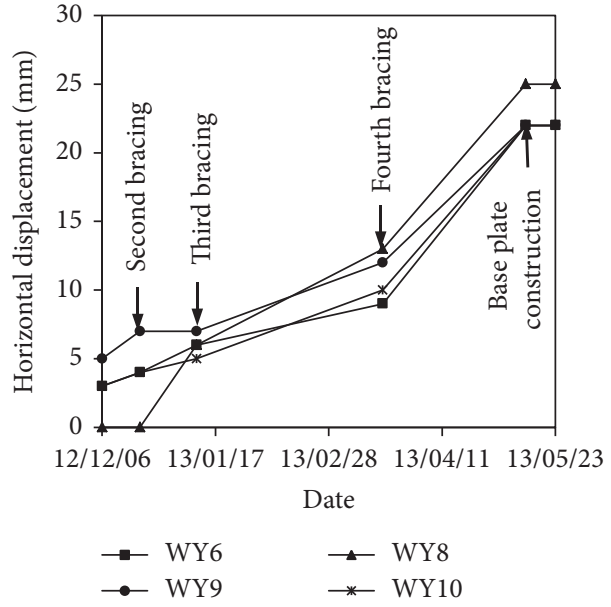

(a)

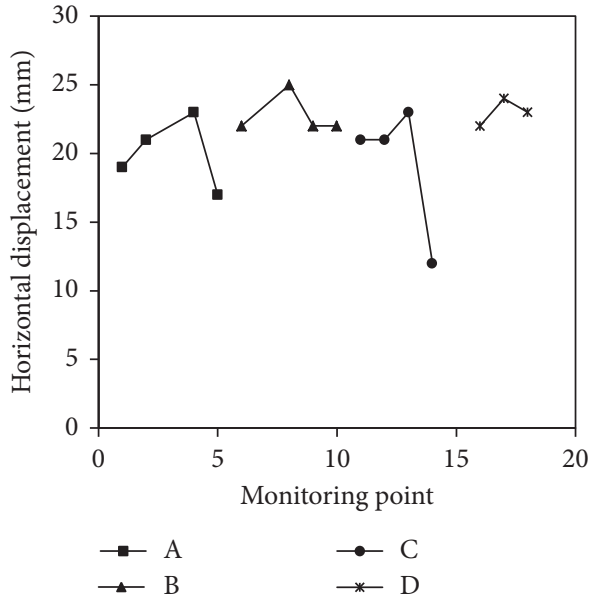

(b)

Figure 5: Horizontal displacement of diaphragm wall top at B side. (a) Time curves of diaphragm wall top at B side. (b) Curves when finishing base plate construction.

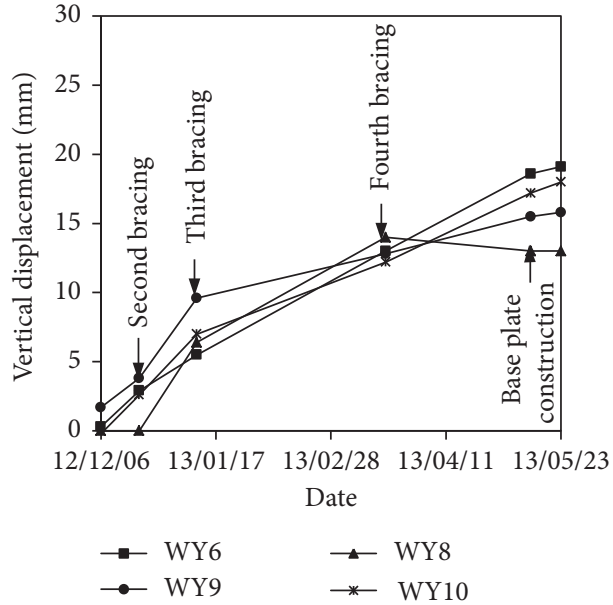

(a)

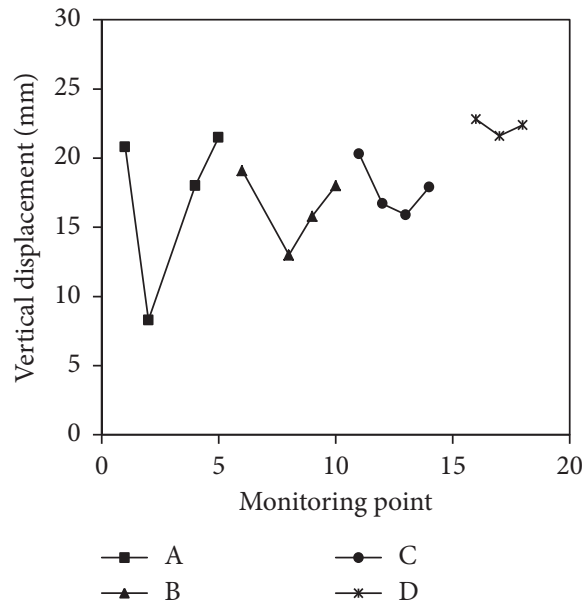

(b)

Figure 6: Vertical displacement of diaphragm wall top at B side. (a) Time curves of diaphragm wall top at B side. (b) Curves when finishing base plate construction.

and the base plate should be poured timely when finishing excavation. The vertical displacement of the diaphragm wall top near the middle part increased with the increasing of excavation depth at the beginning, and then reached an equilibrium level after finishing the fourth bracing.

As shown in Figure 6(b), the vertical displacement of the diaphragm wall top at the same side decreased before rising and showed concave shape. The monitoring point of the minimum vertical displacement located at the middle part of the diaphragm wall. This is because that the unloading effect zone of monitoring point near the foundation pit corner (e.g. WY1, WY5, and WY6) was bigger than that of the monitoring point near the middle part (e.g. WY2 and WY8) affected by the unloading effect of adjacent side, resulting in larger vertical displacement. During construction, the vertical displacement of the diaphragm wall top was less than the alarming value on monitoring and belonged to the safe range.

Time curves of lateral displacement of the diaphragm wall for measuring point CX9 at depth of $12 \mathrm{~m}$ are shown in Figure 7. The lateral displacement of the diaphragm wall overall increased with the increasing of excavation depth. After each bracing was installed, the lateral displacement increased slightly, and then increased with a high rate when the construction of excavation was continuing. The effect of bracing on the diaphragm wall can effectively inhibit the development of lateral displacement, resulting in the slight increase of lateral displacement. However, with the increasing of excavation depth, the inhibitory effect of bracing on lateral displacement weakened obviously due to the rise of the height from bracing to excavation base, resulting in the significant increase of lateral displacement. 


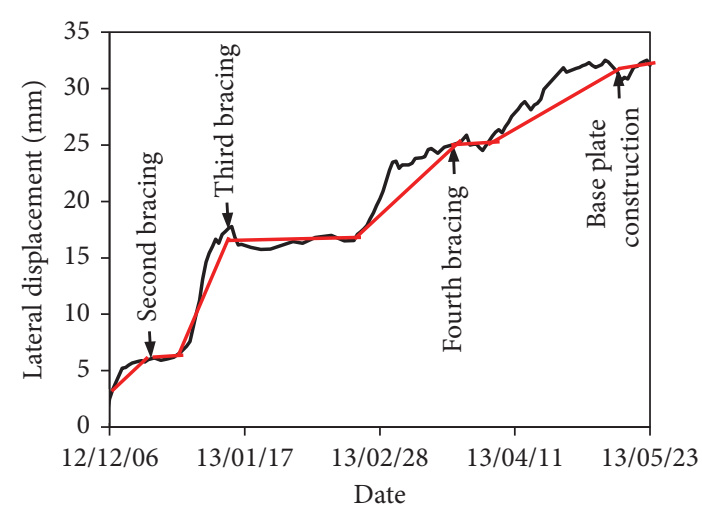

Figure 7: Time curves of lateral displacement of the diaphragm wall for measuring point CX9 at depth of $12 \mathrm{~m}$.

The lateral displacement for monitoring point CX9 is shown in Figure 8. As can be seen, the deformation mode of lateral displacement of the diaphragm wall belonged to the composite mode [19], which had a certain lateral displacement on the wall top and presented convex to the excavation in the middle of the diaphragm wall (see Figure 9). During the first stage excavation, the lateral displacement of the diaphragm wall was small. The maximum lateral displacement was $3.29 \mathrm{~mm}$ and located in the depth of $10 \mathrm{~m}$, which was significant below the first bracing and excavation base. The lateral displacement of the diaphragm wall increased with the increase of excavation depth and the location of maximum lateral displacement developed downwardly near the bracing. The monitoring results agreed with the variation proposed by $\mathrm{Ou}$ [20], which the maximum lateral displacement occurred near the excavation bottom. Hence, strengthening the bracing located in the lower-middle part of excavation depth can reduce the maximum lateral displacement of bracing and retaining structure, resulting in improving the stability of foundation pit. In addition, the lateral displacement appeared in the diaphragm wall bottom when the fourth bracing was installed, indicating that the insertion depth of the diaphragm wall was too short to resist the deformation of the diaphragm wall bottom in the later period of excavation. The deformation mode of the diaphragm wall was the combination of cantilever mode, kick-in mode, and convex mode.

As shown in Figure 8(b), the maximum lateral displacement of the diaphragm wall increased slightly during the preliminary stage and then increased significantly. The relationship between maximum lateral displacement and excavation depth showed a strong linear correlation. The maximum lateral displacement of the diaphragm wall was approximately $36 \mathrm{~mm}$ when excavation was finished.

Figure 10 shows the curves of lateral displacement of the diaphragm wall for different monitoring points at different sides when the construction of the base plate is completed. As can be seen, the deformation mode of the diaphragm walls at different sides belonged to the composite mode, and the maximum lateral displacement of those diaphragm walls occurred near the base plate. The results indicated a similar deformation mechanism of the diaphragm walls at different sides. The difference of maximum lateral displacement between monitoring point $\mathrm{CX} 2$ at $\mathrm{A}$ side and monitoring point CX5 at B side was almost ignored and about $33 \mathrm{~mm}$, while the maximum lateral displacements of monitoring point CX6 at $\mathrm{C}$ side and monitoring point $\mathrm{CX} 9$ at $\mathrm{D}$ side were up to $36 \mathrm{~mm}$, which was greater than that of the monitoring points CX2 and CX5. The bracing and retaining structure used the annular bracing system, and the positions of four monitoring points were overall symmetry along the diagonal line. Hence, the bracing stiffness near the positions of monitoring points was almost same, resulting in similar lateral displacement of different monitoring points. The lateral displacement of monitoring point CX5 below the excavation face was obviously greater than that of monitoring points $\mathrm{CX} 2$, CX6, and CX9, which may be because of the shorter insertion depth of monitoring point CX5. During construction, the lateral displacement of the diaphragm wall was less than the alarming value on monitoring and belonged to the safe range.

4.2. Displacement of Bracing Pillar. The displacement of bracing pillar after finishing construction of the base plate is shown in Figure 11. The horizontal displacement of bracing pillar overall showed a fluctuant trend in the range of 6 14 $\mathrm{mm}$. The horizontal displacements of bracing pillar for monitoring points LZ1, LZ3, LZ5, and LZ7 were smaller than that of monitoring points LZ2, LZ4, LZ6, and LZ8 due to the stronger bracing stiffness around the monitoring points LZ1, LZ3, LZ5, and LZ7, which effectively limited the horizontal displacement. The vertical displacement of bracing pillar was obviously greater than horizontal displacement and varied slightly in addition to monitoring point LZ3, which is similar to the general trends of those for Shanghai World Finance Center excavation pit reported by Tan [14].

4.3. Ground Surface Settlement. The relationship between ground surface settlement and distance from the diaphragm wall is shown in Figure 12. As studied by Clough and O'Rourke [21], the trapezoidal shape of the nondimensional settlement profile was suggested, in which the influence zone of maximum ground surface settlement $\left(\delta_{\mathrm{vm}}\right)$ was $0.75 \mathrm{H}_{\mathrm{e}}$ and then the settlement decreased linearly until zero at $2.0 \mathrm{H}_{\mathrm{e}}$. The excavation depth $\left(\mathrm{H}_{\mathrm{e}}\right)$ was used as a parameter in the normalized relationship. Furthermore, $\mathrm{Hsieh}$ and $\mathrm{Ou}$ [22] suggested that the settlement at wall was $0.5 \delta_{\mathrm{vm}}$ and the maximum ground surface settlement $\left(\delta_{\mathrm{vm}}\right)$ was at $0.5 \mathrm{H}_{\mathrm{e}}$. The primary influence zone was $2.0 \mathrm{H}_{\mathrm{e}}$, and the settlement was equal to $0.1 \delta_{\mathrm{vm}}$. The secondary influence zone was $4.0 \mathrm{H}_{\mathrm{e}}$ and much less steep than the primary influence zone. As shown in Figure 12, the settlement computed using the method of Clough and O'Rourke generally gave a good estimate of the settlement envelope, and all the measuring data were in the range suggested by Clough and O'Rourke. However, the settlement profile computed using the method of Clough and O'Rourke highly predicted the influence zone of maximum ground surface settlement in this case. Comparatively, settlement profile computed using the method of Hsieh and Ou was in good agreement with the 


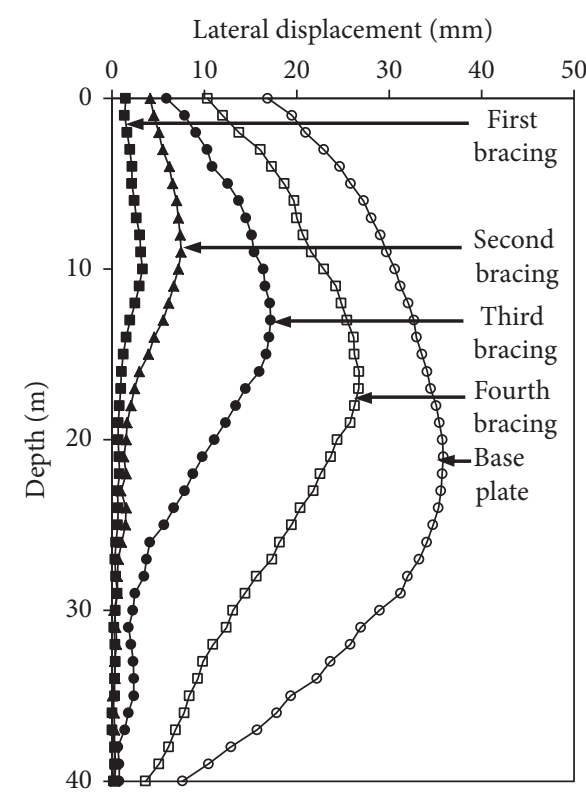

(a)

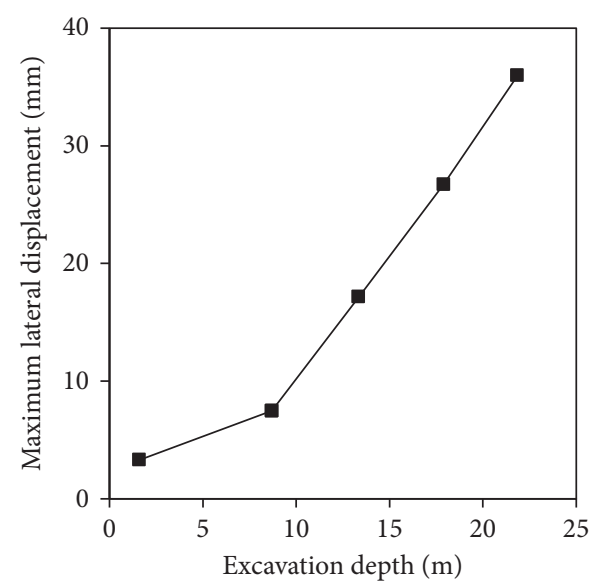

(b)

Figure 8: Lateral displacement for monitoring point CX9. (a) Curves of lateral displacement versus depth. (b) Curve of maximum lateral displacement versus excavation depth.
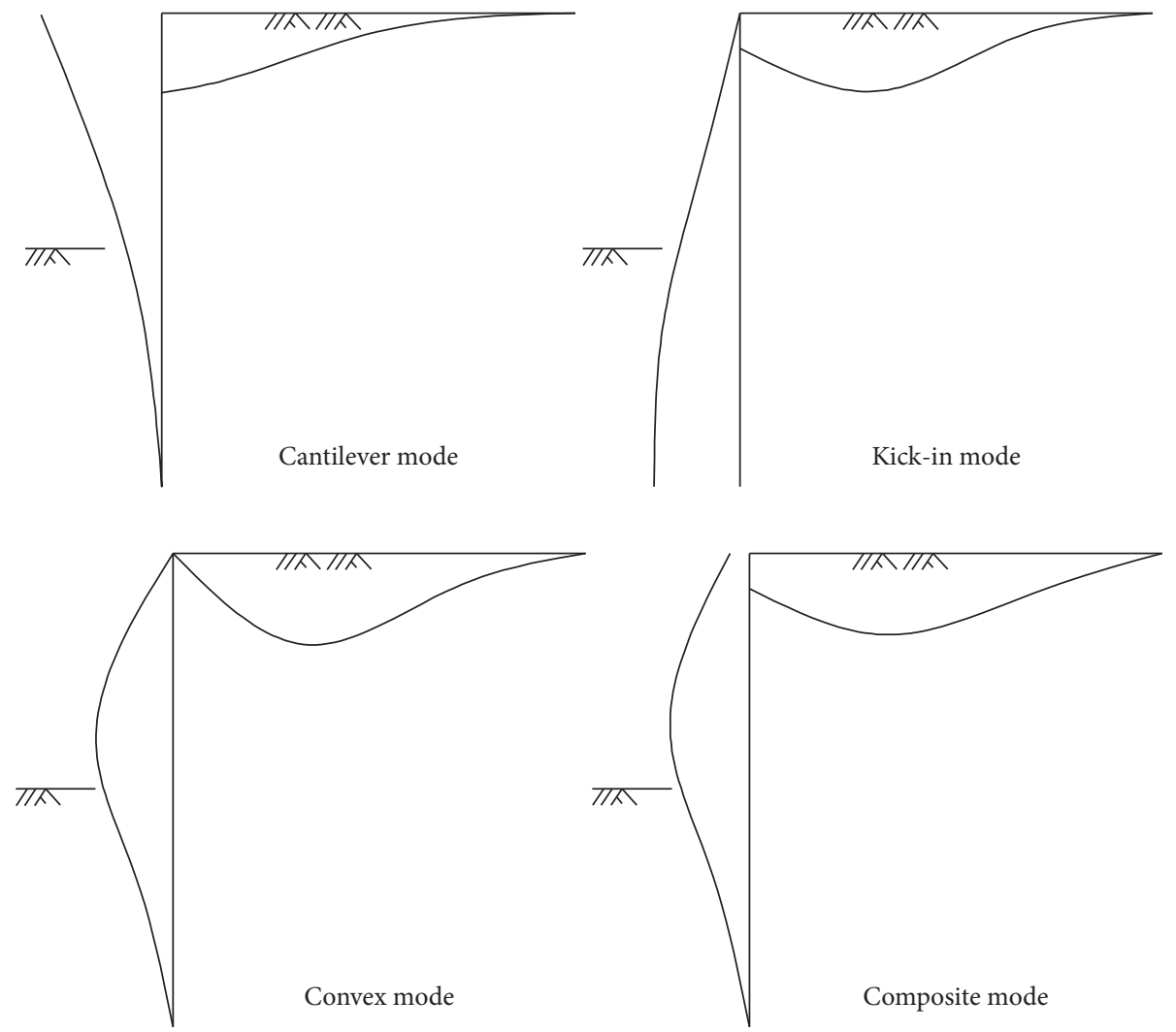

Figure 9: Typical profiles of diaphragm wall deformation.

field observations and better described the development trend of the ground surface settlement.

In general, the maximum ground surface settlement $\left(\delta_{\mathrm{vm}}\right)$ can be estimated by referring to the value of the maximum lateral displacement of the diaphragm wall $\left(\delta_{\mathrm{hm}}\right)$ $[22,23]$. The relationship between the maximum lateral displacement of the diaphragm wall and the maximum ground surface settlements is shown in Figure 13. The 


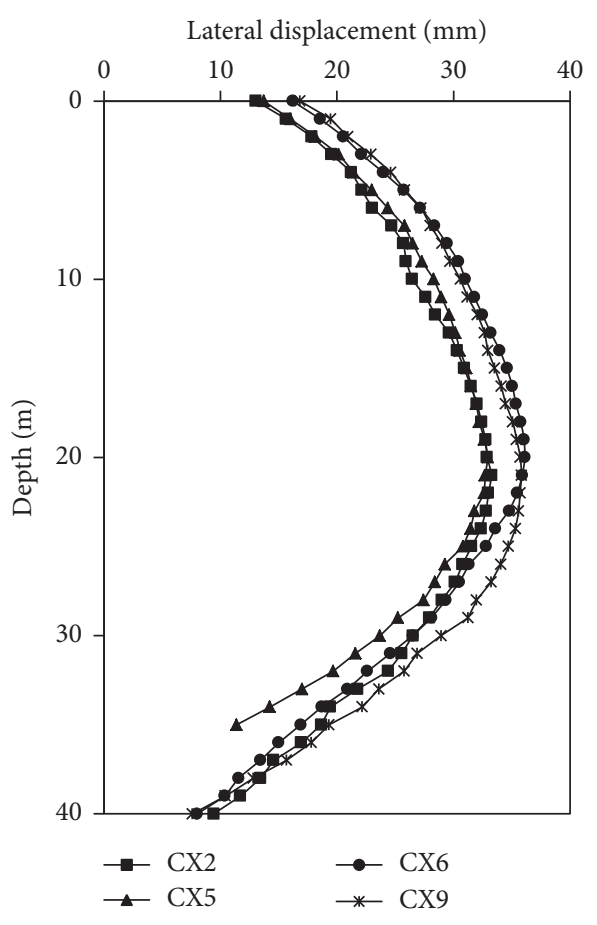

FIGURE 10: Curves of lateral displacement versus depth for different monitoring points.

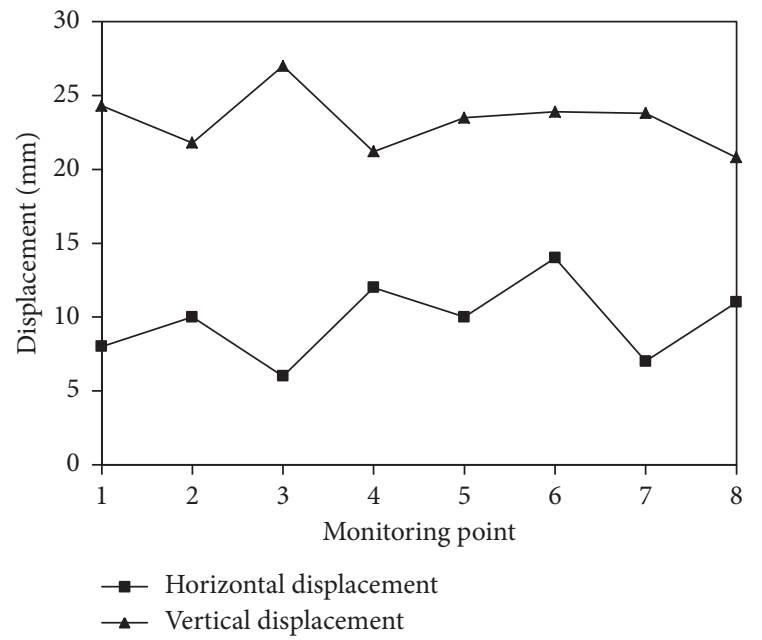

Figure 11: Displacements of bracing pillar after finishing construction of base plate.

findings of Hsieh [22] and Tan [14] were also indicated. As shown in the figure, in the cases proposed by $\mathrm{Hsieh}$ and $\mathrm{Ou}$, $\delta_{\mathrm{vm}}$ was equal to $0.5 \sim 1.0 \delta_{\mathrm{hm}}$, and $\delta_{\mathrm{vm}}$ was equal to $0.3 \sim 1.5 \delta_{\mathrm{hm}}$ for Shanghai World Finance Center excavation pit reported by Tan [14]. However, in this study, $\delta_{\mathrm{vm}}$ was equal to $0.74 \sim 0.88 \delta_{\mathrm{hm}}$. The ratio of $\delta_{\mathrm{vm}}$ to $\delta_{\mathrm{hm}}$ was in the range proposed by Hsieh and Tan and more centralized.

\section{Conclusions}

In this study, the variation trend of the diaphragm wall deformation, displacement of bracing pillar, and ground
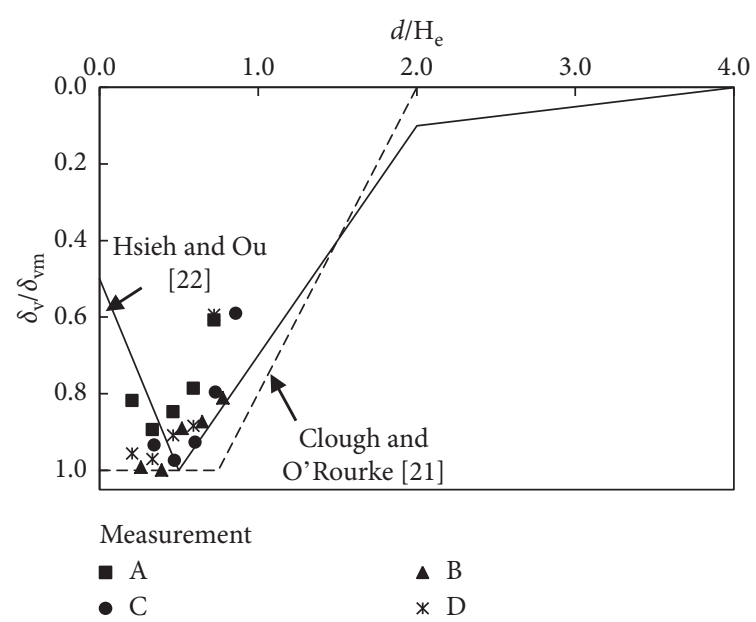

FIgure 12: Relationship between $\delta_{\mathrm{v}} / \delta_{\mathrm{vm}}$ and $d / \mathrm{H}_{\mathrm{e}}$.

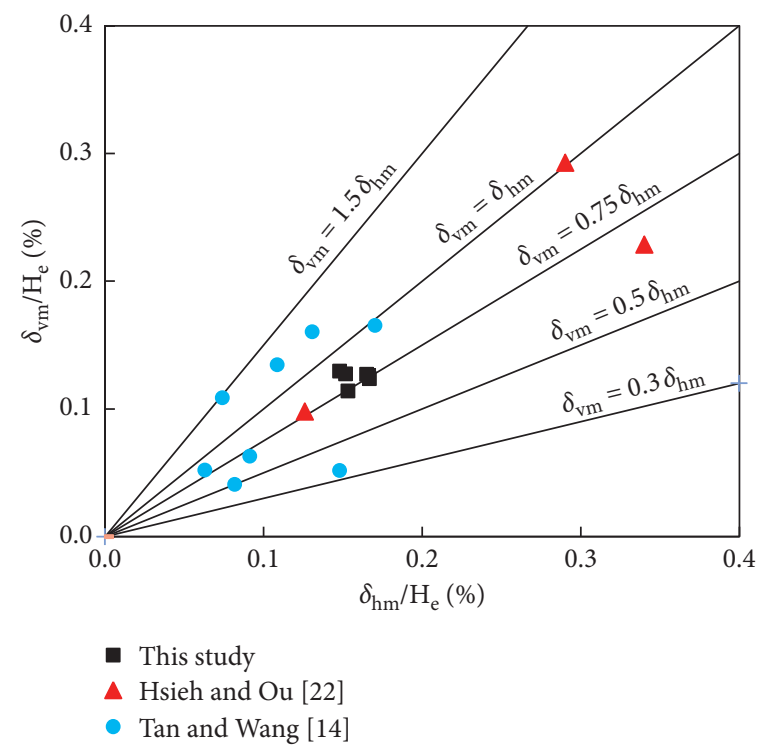

FIgURE 13: Relationship between the maximum lateral displacement of wall and the maximum ground surface settlement.

surface settlement are analysed based on the filed monitoring data during the process of deep foundation pit project in soft soil areas. The following conclusions may be drawn from the results:

(1) The horizontal displacement of the diaphragm wall top at the same side showed convex shape, while the vertical displacement showed concave shape. The horizontal displacement of the diaphragm wall top near the foundation pit corner was smaller when the foundation pit corner was at a less angle.

(2) After each bracing was installed, the lateral displacement increased slightly, and then increased with a high rate when the construction of excavation was continuing. The deformation mode of lateral displacement of the diaphragm wall belonged to the composite mode. The lateral displacement of the diaphragm wall increased with the increasing of 
excavation depth and the location of maximum lateral displacement developed downwardly near the bracing. The relationship between maximum lateral displacement and excavation depth showed a strong linear correlation.

(3) The horizontal displacements of bracing pillar decreased with the increasing of bracing stiffness, while the effect of bracing stiffness on vertical displacements of bracing pillar could be ignored.

(4) The settlement profile computed using the method of Hsieh and $\mathrm{Ou}$ was in good agreement with the field observations and better described the development trend of the ground surface settlement. The ratio of the maximum ground surface settlement $\left(\delta_{\mathrm{vm}}\right)$ to the maximum lateral displacement of the diaphragm wall $\left(\delta_{\mathrm{hm}}\right)$ was in the range of $0.74 \sim 0.88$, belonging to the range of $0.5 \sim 1.0$ proposed by Hsieh and $\mathrm{Ou}$.

\section{Data Availability}

The data used to support the findings of this study are available from the corresponding author upon request.

\section{Conflicts of Interest}

The authors declare that there are no conflicts of interest regarding the publication of this paper.

\section{Acknowledgments}

This research was funded by the Hainan Province Natural Science Foundation of China under Grant no. 20165188 and the Shanxi Province Key Research and Development Projects under Grant no. 201703D321009-2. The financial support is gratefully acknowledged.

\section{References}

[1] R. P. Chen, L. J. Tang, D. S. Ling, and Y. M. Chen, "Face stability analysis of shallow shield tunnels in dry sandy ground using the discrete element method," Computers and Geotechnics, vol. 38, no. 2, pp. 187-195, 2011.

[2] R. P. Chen, J. Zhu, W. Liu, and X. W. Tang, "Ground movement induced by parallel EPB tunnels in silty soils," Tunnelling and Underground Space Technology, vol. 26, no. 1, pp. 163-171, 2011.

[3] R.-p. Chen, J. Li, L.-g. Kong, and L.-j. Tang, "Experimental study on face instability of shield tunnel in sand," Tunnelling and Underground Space Technology, vol. 33, pp. 12-21, 2013.

[4] G. Zheng, Y. Du, X. Cheng, Y. Diao, X. Deng, and F. Wang, "Characteristics and prediction methods for tunnel deformations induced by excavations," Geomechanics and Engineering, vol. 12, no. 3, pp. 361-397, 2017.

[5] Z. Ding, X.-j. Wei, and G. Wei, "Prediction methods on tunnel-excavation induced surface settlement around adjacent building," Geomechanics and Engineering, vol. 12, no. 2, pp. 185-195, 2017.

[6] D. F. Laefer, S. Ceribasi, J. H. Long, and E. J. Cording, "Predicting RC frame response to excavation-induced settlement," Journal of Geotechnical and Geoenvironmental Engineering, vol. 135, no. 11, pp. 1605-1619, 2009.

[7] D. E. Cording, C. F. Leung, and Y. K. Chow, "Behavior of pile groups subject to excavation-induced soil movement in very soft clay," Journal of Geotechnical and Geoenvironmental Engineering, vol. 135, no. 10, pp. 1462-1474, 2009.

[8] C.-Y. Ou and P.-G. Hsieh, "A simplified method for predicting ground settlement profiles induced by excavation in soft clay," Computers and Geotechnics, vol. 38, no. 8, pp. 987-997, 2011.

[9] Y. Tan and M. Li, "Measured performance of a $26 \mathrm{~m}$ deep topdown excavation in downtown Shanghai," Canadian Geotechnical Journal, vol. 48, no. 5, pp. 704-719, 2011.

[10] Y. Tan and B. Wei, "Observed behaviors of a long and deep excavation construction by cut-and-cover technique in shanghai soft clay," Journal of Geotechnical and Geoenvironmental Engineering, vol. 138, no. 1, pp. 69-88, 2011.

[11] R. Chen, F. Meng, Z. Li, Y. Ye, and J. Ye, "Investigation of response of metro tunnels due to adjacent large excavation and protective measures in soft soils," Tunnelling and Underground Space Technology, vol. 58, pp. 224-235, 2016.

[12] G. B. Liu, P. Huang, J. W. Shi, and C. W. W., "Performance of a deep excavation and its effect on adjacent tunnels in shanghai soft clay," Journal of Performance of Constructed Facilities, vol. 30, no. 6, article 04016041, 2016.

[13] G. Ng, X. Deng, C. Liu et al., "Comparative analysis of influences of different deformation modes of retaining structures on displacement field of deep soils outside excavations," Chinese Journal of Geotechnical Engineering, vol. 36, no. 2, pp. 273-285, 2014.

[14] Y. Tan and D. Wang, "Characteristics of a large-scale deep foundation pit excavated by the central-island technique in shanghai soft clay. I: bottom-up construction of the central cylindrical shaft," Journal of Geotechnical and Geoenvironmental Engineering, vol. 139, no. 11, pp. 1875-1893, 2013.

[15] Y. Tan and D. Wang, "Characteristics of a large-scale deep foundation pit excavated by the central-island technique in shanghai soft clay. II: top-down construction of the peripheral rectangular pit," Journal of Geotechnical and Geoenvironmental Engineering, vol. 139, no. 11, pp. 1894-1910, 2013.

[16] Y. Tan, B. Wei, Y. Diao, and X. Zhou, "Spatial corner effects of long and narrow multipropped deep excavations in shanghai soft clay," Journal of Performance of Constructed Facilities, vol. 28, no. 4, article 04014015, 2014.

[17] Y. Tan, B. Wei, Y. Lu, and B. Yang, "Is basal reinforcement essential for long and narrow subway excavation bottoming out in shanghai soft clay?," Journal of Geotechnical and Geoenvironmental Engineering, vol. 145, no. 5, article 05019002, 2019.

[18] H. W. Ying and Y. W. Yang, "Characteristics of a large and deep soft clay excavation in Hangzhou," Chinese Journal of Geotechnical Engineering, vol. 33, no. 12, pp. 1838-1846, 2011.

[19] X. N. Gong and Y. C. Gao, Construction and Design Manual of Deep Excavation Engineering, China Architecture and Building Press, Beijing, China, 1998, in Chinese.

[20] C.-Y. Ou, P.-G. Hsieh, and D.-C. Chiou, "Characteristics of ground surface settlement during excavation," Canadian Geotechnical Journal, vol. 30, no. 5, pp. 758-767, 1993.

[21] G. W. Clough and T. D. O'Rourke, "Construction-induced movements of in situ walls," in Proceedings, Design and Performance of Earth Retaining Structures, pp. 439-470, ASCE Special Conference, Ithaca, NY, USA, 1990. 
[22] P. G. Hsieh and C. Y. Ou, "Shape of ground surface settlement profiles caused by excavation," Canadian Geotechnical Journal, vol. 35, no. 6, pp. 1004-1017, 1998.

[23] A. I. Mana and G. W. Clough, "Prediction of movements for braced cut in clay," Journal of the Geotechnical Engineering division, ASCE, vol. 107, no. GT8, pp. 759-777, 1981. 


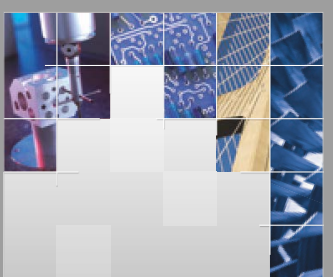

\section{Enfincering}
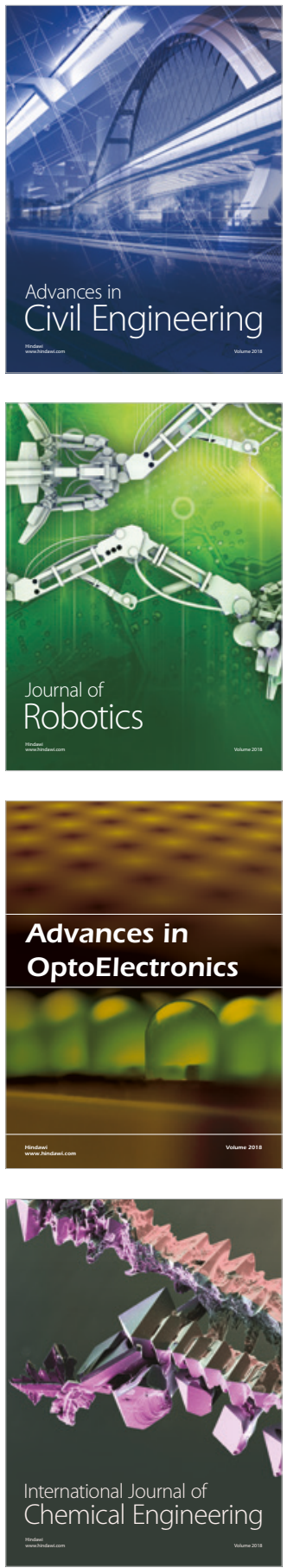

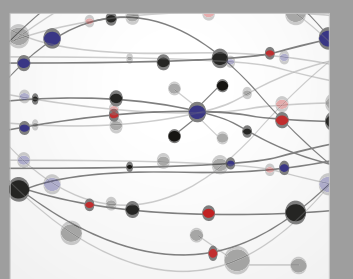

\section{Rotating \\ Machinery}

The Scientific World Journal

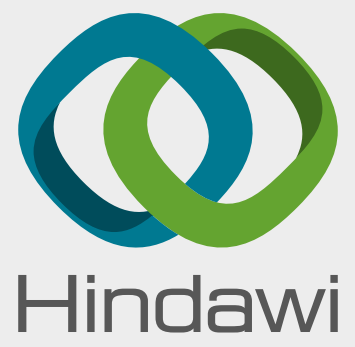

Submit your manuscripts at

www.hindawi.com
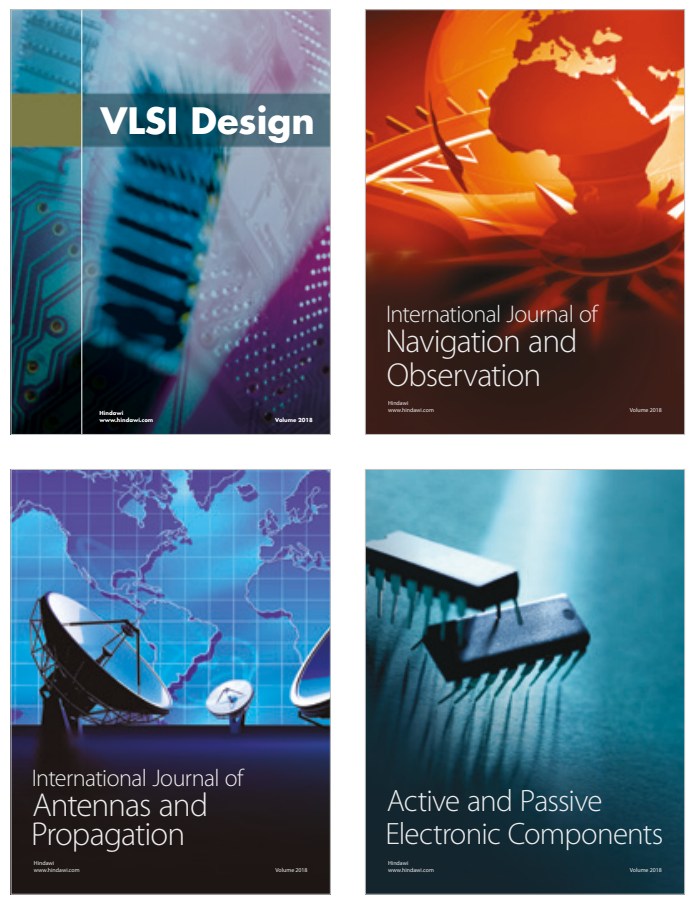
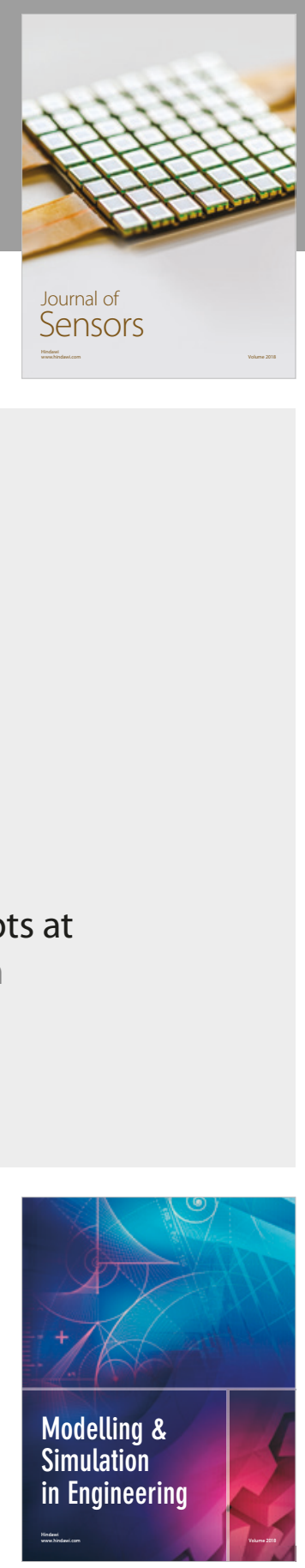

\section{Advances \\ Multimedia}
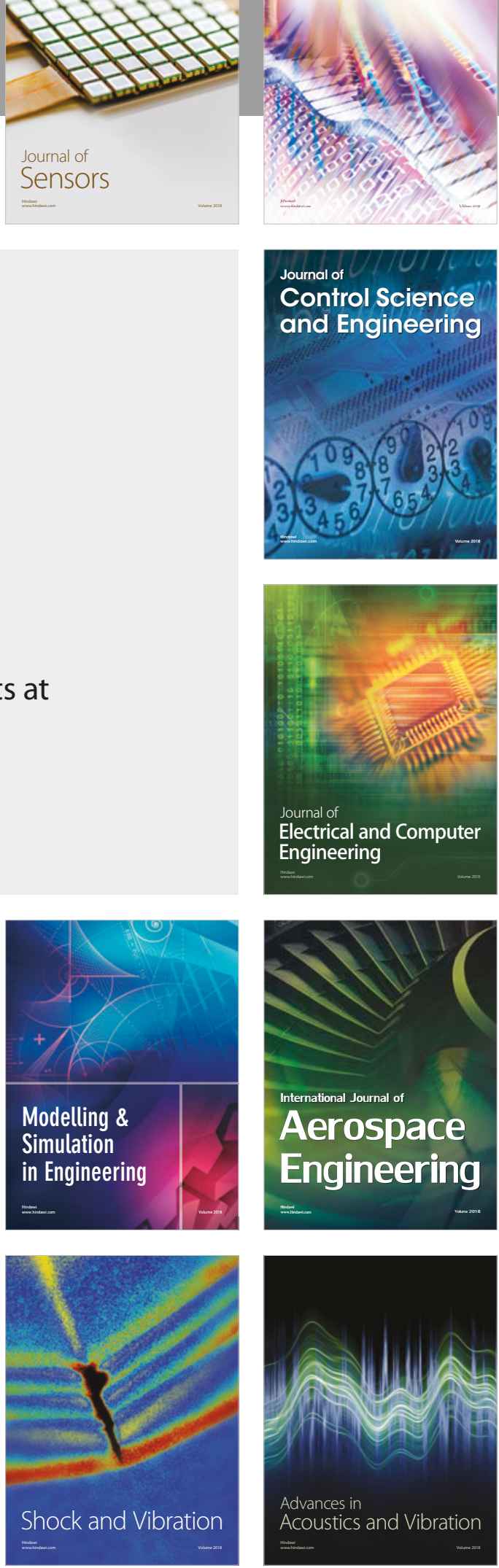